\title{
Cognitions of Supervisors-In-Training: An Exploratory Study
}

By: L. DiAnne Borders, Margaret L. Fong

This is the pre-peer reviewed version of the following article: Borders, L. D., \& Fong, M. L. (1994). Cognitions of supervisors-in-training: An exploratory study. Counselor Education and Supervision, 33(4), 280-293., which has been published in final form at http://onlinelibrary.wiley.com/doi/10.1002/j.1556-6978.1994.tb00294.x/abstract.

\begin{abstract}
:
Explores supervisor development using multiple measures with nine supervisors-in-training. Difficulty in assuming the supervisor role and dealing with relationship dynamics; Supervision as an essential element of counselor development; Three brief models of supervisor growth; Determination of developmental levels; Changes in supervisors' conceptualizations about the supervision enterprise.
\end{abstract}

Keywords: Counseling | Supervisors | Education

\section{Article:}

Multiple measures were used with nine supervisors-in-training to explore supervisor development. Students' responses suggested some difficulty in assuming the supervisor role and dealing with relationship dynamics.

Although supervision is considered an essential element of counselor development, little attention has been given to the development of supervisors. Three brief models of supervisor growth have been proposed. First, Alonso $(1983,1985)$ proposed a psychodynamic "developmental map" covering three phases of novice, midcareer, and late career. In this model, supervisors strive to meet developmental needs in each stage as they contend with intrapsychic, interpersonal, and sociopolitical forces that influence their behavior. Novices are characterized by overidentification with the counselor or by overly critical and demanding behavior. In a second model, Hess $(1986,1987)$ outlined a more atheoretical view of supervisor development. Across three stages (i.e., beginning, exploration, and confirmation of supervisor identity), supervisors gradually understand and accept supervision as a unique professional activity, educate themselves about the role, give more priority to students' learning needs, and achieve more mutuality in their supervisory relationships. Beginning-stage supervisors often are quite self-conscious, formal, and task-oriented, preferring to focus on concrete issues (e.g., client diagnosis, teaching techniques). Stoltenberg and Delworth (1987) proposed a third model that parallels their developmental model of counselor growth. Developmental levels are determined by supervisors' level of counselor development and their training and experience in supervision. At early levels, supervisors tend to be anxious, naive, highly motivated, self-focused, 
apprehensive about doing the "right" thing, fairly structured, and dependent on their own supervisor.

These brief models provide a consistent but general, conceptual view of supervisor development (see also Worthington, 1987), particularly for novice supervisors. To date, however, there have been no direct, empirical tests of these models. Some limited, indirect support can be found in the few published studies of novice supervisors. Beginning supervisors surveyed by McColley and Baker (1982) reported their most frequent difficulties were dealing with counselor resistance, feeling they did not know what was happening in a case, and not knowing what interventions to suggest. They characterized their role as teacher and model and indicated that they focused supervision sessions primarily on the client. In two studies of doctoral-level supervisors' verbal patterns (Holloway, 1982; Holloway \& Wampold, 1983), participants primarily used supportive and informational responses but viewed their use of supportive statements negatively. Heppner and Handley (1981) found that doctoral-level supervisors (and their supervisees) believed supervision had minimal influence on changing counselors' personal and professional attitudes and behavior. More recently, Ellis (1991) asked supervisor-trainees to describe any critical incidents that occurred after each supervisor-counselor session and after each supervisor-supervisor session during a brief supervision practicum. He found that, similar to novice counselors, novice supervisors reported critical incidents primarily related to the supervisory relationship, competence, emotional awareness, and autonomy. Relatively few critical incidents involved personal issues, individual differences, professional ethics, theoretical identity, purpose and direction, or personal motivation.

As previously suggested, both models of supervisor development and empirical studies of beginning supervisors characterize novices as anxious, self-doubtful, and leery of being evaluative or confrontational. There is little flexibility in approach, with novices tending to be highly supportive and/or didactic, concrete, structured, and task-oriented. These limited results are informative about the characteristics of novices, but they offer little information about how supervisors progress through developmental levels, taking on the role and forming a supervisor identity. Information about how supervisors develop self-efficacy and learn to apply their supervision knowledge and skills would be particularly helpful for supervisor educators.

Several writers (e.g, Bernard \& Goodyear, 1992; Borders, 1989, in press; Heath \& Storm, 1983) have indicated that a key to understanding supervisor development is charting changes in supervisors' conceptualizations about the supervision enterprise. These authors believe that the "cognitive shift" (Heath \& Storm, 1983) from thinking like a counselor (e.g., focusing on client dynamics) to thinking like a supervisor (e.g., focusing on counselor's educational needs) is pivotal to supervisor development. They see this cognitive change as the first step in creating a conceptual framework for conducting supervision and taking on the role and professional identity of a supervisor. This view of supervisor development suggests that researchers should give attention to supervisor trainees' thoughts about themselves and their new tasks (see also 
Bernard \& Goodyear, 1992). To date, however, no writers have specified elements of the cognitive shift.

In an effort to provide initial information about supervisor development, this study was designed to describe novice supervisors' cognitions about the supervision enterprise and any differences in these cognitions over a limited time period (i.e., one-semester supervision practicum). Given the lack of systematic work in this area, we elected to conduct a discovery-oriented (e.g., Mahrer, 1988) investigation designed to identify salient variables. Discovery-oriented research, also referred to as exploratory process research, is built on a sequential scientific method by which counseling (or supervision) events are observed; hypotheses are formulated, tested, and refined; and, eventually, theory is developed (Hill, 1990). In light of the limited theory and descriptive information about supervisor development, this approach seemed most relevant. Based on previous supervision literature (cited previously), three broad descriptive areas of cognitions were targeted for this investigation: (a) content of thoughts (e.g., focus, tone), (b) choice of interventions within a particular supervisory context, and (c) self-appraisal regarding the supervisor role.

\section{METHODOLOGY}

\section{Participants}

Participants were enrolled in two CACREP-approved programs in counselor education. Eight doctoral-level students (7 women, 1 man) and one specialist-level (EdS.) female student enrolled in required supervision practicums volunteered to participate in the study. Four were students in a large, southeastern university; the other five were at a medium-size, southeastern university. Participants' ages ranged from 30 to $52(\mathrm{M}=37.00$, $\mathrm{SD}=6.42)$; all were White. Students from both programs reported somewhat similar amounts of prior experience in teaching (Group 1, M = 4.5 years; Group 2, $M=9$ years), counseling (Group 1, $M=4.5$ years; Group 2, $M=5$ years), and supervision in counseling settings (administrative, clinical or both) (Group 1, M = 1 year; Group $2, \mathrm{M}=.625$ ). None had completed formal coursework in counseling supervision.

At the time of the study, students were enrolled in a supervision practicum experience at their respective universities and had been assigned to the researchers for group supervision. In turn, each student was assigned 1 or 2 master's-level interns for weekly, individual supervision. (These assignments were made by internship coordinators not involved in the study.) Student supervisors themselves received individual and group supervision each week, consisting primarily of reviews of their videotaped sessions; the researchers conducted the weekly group supervision sessions (1 1/2 hours) at their respective universities. During initial group meetings, both instructors focused on structuring supervision sessions appropriately, assuming the supervisor role, and identifying supervisee learning needs. In subsequent group sessions, a case presentation format was used; at least 1 student presented a videotape for group review each week. 


\section{Variables and Procedure}

Information was gathered over time on content of thoughts, supervisors' choices of interventions, and supervisors' appraisals of their supervision experiences. All three measures were administered during group supervision sessions in the 2nd and 15th weeks of the semester. During the first test administration, students read and signed a consent form and completed a demographic questionnaire; none declined to participate in the study. During both test administrations, they responded to the critical incidents instrument (choice of interventions within a particular context), thought-listing exercise (content of thoughts), and self-appraisal scale (in that order).

Content of thoughts. To assess the nature of students' thoughts about supervision issues, a thought-listing exercise was developed following guidelines outlined by Cacioppo and Petty (1981). The thought-listing approach allows researchers to assess (e.g., categorize) a person's cognitions in response to a specific stimulus and has been found to be a promising method for counseling research (e.g., Heppner, Rosenberg, \& Hedgespeth, 1992). Per standard procedures, the instrument for reporting thoughts consisted of one page of directions and a written vignette depicting a critical incident in supervision (taken from the Critical Incidents in CounselorSupervision -Form A [CICS]) (Black, 1990), and four pages of empty boxes for recording thoughts. The directions page, which also was read to participants, included an explanation of the thought-listing procedure, indicated that the students were to write only one thought per box and asked students to be spontaneous, open, and honest in their responses.

Students were asked to respond to the following vignette:

The counselor you are supervising has a client who usually arrives for his session at least 10 minutes late and has not shown up for one session (he later explained that he simply forgot). The counselor has expressed irritation at this behavior but has failed to recognize that he has a similar pattern for supervision sessions with you. Counselor: When he's late or doesn't come, I feel resentful. Supervisor: Do you believe this is a pattern? Counselor: Yes, I think so.

This particular vignette was chosen because it seemed to allow for a range of responses, offered the opportunity to consider supervision relationship dynamics, including parallel process, and provided possibilities for a variety of interventions. After the vignette was read aloud, students had 3 minutes to list as many thoughts as they had about the supervision incident. Content codes for analyzing the thought-listings were based on existing coding systems for cognitions about interpersonal situations (Dole et al., 1982; Duck, 1973). One dimension, analytic style, was added after study of the responses indicated this theme was not being assessed adequately by the preexisting content codes. Thus, each thought was classified into one category on each of four separate dimensions: (a) focus (client, counselor, supervisor, counselor-client, counselorsupervisor, parallel process); (b) content (physical or factual, roles or habitual behaviors, psychological traits, interactional or process-oriented); (c) tone (positive, negative, neutral); and 
(d) analytic style (restatements of facts given in the vignette, assumptions or judgments, inquiry or divergent thoughts, directives or action-oriented thoughts).

Choice of interventions. The Critical Incidents in Counselor Supervision-Form B (CICS-B) (Black, 1990) was used to assess students' preferred supervision interventions within a particular context. The CICS-B consists of nine vignettes that depict a wide range of supervision-related issues (e.g., beginning counselor who is highly anxious, counselor who has difficulty when her clients express anger, counselor who reports that she is experiencing concerns similar to those of her client). After reading each vignette, respondents rank order four alternative responses and, for seven of the vignettes, also rate the appropriateness or importance of each of four alternative responses ( 1 = highly inappropriate or irrelevant, 5 = highly appropriate or highly important), for a total of 17 items.

The CICS vignettes were written to reflect requisite components of effective supervision (Dye \& Pride, 1987) and actual critical incidents reported by doctoral students with supervision experience. Final vignettes were chosen based on their face validity and lack of duplication. Questions about each vignette were focused on identifying the central issue, choosing an appropriate intervention, and recognizing ethical considerations. Expert raters with an average of 15 years supervision experience were used to establish a "correct" response on each item.

Black (1990) reported reliability estimates ( $\mathrm{n}=16$ experienced counselor educators) ranging from. 17 to 1.0, with kappas of. 51 or higher for 8 of 17 questions on CICS-B. She also reported that experienced supervisors had significantly higher scores (i.e., they agreed with the expert raters) than did two groups of counseling students with no supervisor experience. Black (1990) concluded that, although some revisions were needed for several items, the critical incident simulation approach was useful in describing differences between supervisors at various levels of supervision experience. Although Black's (1990) psychometric data for the CICS--B was somewhat problematic, we chose to use it because it allowed an in-depth look at individuals' intervention preferences in response to the same supervision stimuli.

Cognitive appraisal of supervision. The Stress Appraisal Scale (SAS: Carpenter \& Suhr, 1988) was used as a measure of students' cognitive appraisal of their ability to perform as a supervisor (self-efficacy) and the extent to which providing supervision was perceived as stressful. The SAS consists of 36 items covering six domains thought to be part of the stress appraisal process for any activity that involves performance. The instrument is tailored to a specific task by the introductory directions. For this study, the directions were to "Answer the following questions according to how you are feeling about doing supervision." A 4-point Likert scale (1 = very untrue of me to 4 = very true of me) is used to respond to the 36 items (e.g., "This sounds very demanding"; "I will handle this just fine"). Item responses are then summed to obtain three subscale (factor) scales. 
Internal consistency estimates for the six domains ranged from .77 to .90 (coefficient alphas) (Carpenter \& Suhr, 1988). A principal axis factor analysis yielded three factors (subscales): (a) secondary or self-appraisal (skills/resources for coping and prediction of success), (b) difficulty (demands of the task and perceptions of one's stress level), and (c) salience (caring about one's performance and recognizing consequences for self). Carpenter and Suhr (1988) also reported an initial study of concurrent validity; college students completed the SAS and measures of interpersonal competence, emotional reactions, and stress reactions. Correlations between these measures and the SAS subscales ranged from .38 to .66 for secondary appraisal, .37 to .66 for difficulty, and .02 to .52 for salience.

In this study, the two factors with higher validity (difficulty of the task and secondary or selfappraisal) seemed most relevant to cognitive appraisal of supervision; thus, only these two factors were included for data analysis. Possible range of scores on each subscale was 12 to 48.

\section{Data Analysis}

In light of the exploratory nature of this investigation, both quantitative and qualitative analyses were conducted. Quantitative approaches were used to test for significant differences between responses at each test administration (e.g., categories of thought content, scores for selected interventions, self-appraisal scores). Qualitative approaches were used in two instances: (a) in a profile analysis of supervisors' thought content and (b) in a comparison of participants' intervention choices with the choices of experts.

\section{RESULTS}

\section{Content of Thoughts}

Thought-listing data for each test administration was available for eight students. The eight reported 4 to 12 thoughts at the first test administration $(\mathrm{M}=8.00, \mathrm{SD}=3.16)$ and 2 to 10 thoughts at the second $(\mathrm{M}=7.25, \mathrm{SD}=2.43)$. A t test for nonindependent samples indicated no significant difference between the total number of thoughts reported at the two test administrations, $\mathrm{t}(7)=-0.66$. Two trained raters, who had previous experience using the coding systems in studies of counselors' cognitions, independently classified each thought on the four dimensions. Interrater agreement ranged from $86.89 \%$ (content dimension) to $97.56 \%$ (tone). Proportion of thoughts in each category within each dimension was calculated for every student and for the entire sample (see Table 1).

To determine any differences in patterns of thought content, tests for binomial proportion were performed. This particular analysis was necessary because of the small sample size, small number of total thoughts, and the number of empty cells for each participant. In this instance, the binomial test was used to determine whether the proportion of students whose thought patterns changed in the hypothesized direction exceeded the proportion expected by chance. Separate tests were conducted for each category within each dimension (e.g., 6 tests for Focus categories), 
with a total of 17 tests conducted. Results indicated there were no significant differences in students' thought patterns at the two test administrations.

At both test administrations, students' thoughts in reaction to the vignette were primarily focused on the counselor and the supervisor (self); concerned roles or habitual behaviors, psychological traits, and (to a lesser extent) the supervisory interaction; were predominately neutral, with few negative and no positive thoughts; and expressed directive/action-oriented and inquiry-divergent thoughts. Scrutiny of individual profiles revealed several shifts in thought content. There was an increase from I to 5 students who considered the parallel process dynamic, and the 5 students who expressed negative thoughts at Time 1 reported smaller proportions of these thoughts at Time 2.

\section{Choice of Supervisory Interventions}

Scores for the CICS-B were determined by comparing students' responses with those of experts (Black, 1990). One point was awarded if the students' first choice matched the experts' first choice. This procedure yielded a total possible score of 17 . At the first test administration, scores for the 9 students ranged from 3 to $13(\mathrm{M}=10.11$, SD = 3.26); at the second administration, scores ranged from 6 to $13(\mathrm{M}=10.67, \mathrm{SD}=2.69)$.

A t test for nonindependent samples yielded no significant difference between scores for the two test administrations, $\mathrm{t}(8)=0.97$. This result suggested that, overall, students did not change in their responses to the supervision vignettes. Concerned that differences may have been masked by the range of difficulty of the items (i.e., no change revealed if items were too easy or too difficult), we conducted an item analysis to determine the degree of difficulty of each item at each test administration. The item analysis revealed a restricted range of difficulty. For example, at the first test administration, only 3 items had a degree of difficulty of .30 or below (i.e., 6 or more students answered correctly; 3 or fewer students answered incorrectly), and only 3 items had a degree of difficulty of .67; on no item did 7 or more students answer incorrectly.

Several patterns were noted in students' responses, particularly in comparing their responses with those of the expert raters. First, students tended to choose clinical interventions over the educational interventions preferred by experts. For example, students chose to take over for a highly anxious intern rather than provide the intern with needed instruction, support, and encouragement. Similarly, students tended to focus on the client rather than on the counselor in their choices (e.g., they chose to address the client's resistance rather than the counselor's skill deficit in handling this resistance). Students sometimes agreed with experts on the central issue within a particular vignette but disagreed on the appropriate response. For example, students were able to recognize a counselor's anxiety with little difficulty, but chose a course of action that could have increased anxiety and self-doubt (taking over in a noncrisis situation) rather than helping the counselor cope with that anxiety. 
A second pattern was a directive vs. nondirective choice; students either were confrontational or positive and supportive. In one instance in which a confrontational or direct intervention was the preferred choice (counselor's sexist behavior), students instead choose a more indirect route ("discuss with the counselor his views about the role of women in society"). They particularly avoided relationship issues, both in the supervisory relationship (e.g., supervisee resistance) and the counseling relationship (e.g., cross-cultural and cross-gender issues). Scrutiny of responses to each vignette revealed a shift away from the experts' preferred intervention for one vignette. In this vignette, a counselor reported that she feared personal problems were interfering with her counseling. At the first test administration, 7 of the 9 students agreed with experts that the supervisor should acknowledge the counselor's problem and then explore how each might be influencing her counseling performance. At the second administration, however, 5 students believed the supervisor should either advise the student to get personal counseling or "insist that supervision conversation be related to clients and counseling activity." Thus, at the end of the supervision practicum, students tended to choose a response that clearly rejected addressing the counselors' personal concern.

\section{Cognitive Appraisal of Supervision}

Respondents' ratings on the SAS were summed to obtain appraisal subscale scores for difficulty of the task and secondary (self-) appraisal. Higher scores on the SAS indicate appraisals of greater task difficulty and more negative appraisals of one's ability to cope with the task. At time 1 , scores on the difficulty subscale ranged from 25 to $44(\mathrm{M}=34.56, \mathrm{SD}=6.19)$; those on the secondary self-appraisal subscale ranged from 12 to $38(\mathrm{M}=21.56$, $\mathrm{SD}=9.37)$. Preliminary analyses indicated significant differences between the pretest scores of students in the two university settings, requiring the use of separate t-tests for nonindependent samples to test for differences between scores at the two test administrations. No significant results were found for the difficulty subscale, $\mathrm{t}(4)=-1.90$ and $\mathrm{t}(3)=-1.22$, nor for the self-appraisal subscale, $\mathrm{t}(4)=$ -2.97 and $t(3)=1.41$. At time 2 , students overall tended to rate supervision as less difficult and themselves as better able to cope; in addition, their posttest scores were more homogenous (difficulty scale $\mathrm{M}=31.33, \mathrm{SD}=3.77$; self-appraisal scale, $\mathrm{M}=16.78$, $\mathrm{SD}=4.35$ ).

\section{DISCUSSION}

This study provided initial descriptions for three types of beginning supervisors' thoughts about supervision and indicated that these thoughts change little over the course of a one-semester supervision practicum. Results for each type of cognition are summarized in this section.

First, in terms of content of thoughts in response to a particular vignette, students in this study listed various assumptions about the counselor or situation, considered other influencing factors (inquiry-divergent thinking mode), and gave considerable attention to what actions they would take. They listed few thoughts about concrete aspects of the vignette (i.e., physical or factual information, restatements of facts). Their thoughts were primarily neutral, suggesting that they 
were able to be nonjudgmental and objective, at least in response to the selected written vignette. No positive thoughts were listed at either test administration. Whereas it can be speculated that novice supervisors do not consider positive aspects of a supervision situation, it also could be that aspects of the example vignette engendered neutral and negative reactions. Second, students' intervention choices for specified situations often conflicted with those of expert supervisors, suggesting that they had some difficulty assuming the supervisor role. They tended to choose interventions directed at the client rather than at the counselor, even when they recognized that a counselor-focused issue was central to the successful resolution of a particular situation (vignette). Students' responses also seemed to be dichotomized (e.g., selected interventions were either supportive or confrontational), and, at the end of the practicum, they seemed to avoid offering supervisees counseling-type interventions. Dichotomous thinking is often associated with rule-bound systems of thinking (Beck \& Freeman, 1990), suggesting that the students may have taken on rigid rules about the conduct of supervision. It seems that supervisor development may be similar to the process of counselor development (cf. Stoltenberg, 1981), such that supervisors first take on black-and-white, categorical thinking before they are able to differentiate and see subtleties in a particular situation.

In addition, students seemed particularly challenged by situations that required interventions focused on relationship dynamics. This result was similar to difficulties reported by novices in McColley and Baker's (1982) study. Issues such as supervisee resistance, and cross-cultural and cross-gender issues may be difficult for novices: supervisors may need to gain some experience and confidence before they are ready to tackle such issues (cf. Borders et al., 1991).

Third, in terms of cognitive self-appraisal, students generally saw the task of supervision as fairly difficult, reporting relatively high stress and negative assessments of their ability to cope with the task and to be successful. In line with the limited literature on novice supervisors (e.g., McColley \& Baker, 1982; Stoltenberg \& Delworth, 1987), students seemed somewhat overwhelmed by the task of supervision, even at the end of the one-semester practicum.

Several limitations of this study should be kept in mind when considering the results. First, there is the problem of low power increasing the chance of a Type II error (i.e., failing to detect an actual change). Second, the small number of participants may have affected the ability to detect differences. On the thought-listing measure, for example, the need to employ the binomial test limited the possibility of achieving significance with this sample: some potentially relevant differences were not picked up by this analysis (e.g., there was an increase from 1 to 5 students who considered the parallel process dynamic, and the 5 students who expressed negative thoughts at Time 1 reported smaller proportions of these thoughts at Time 2). The limited supervision experience offered via the practicum (i.e., each student supervised only 1 or 2 interns for one semester) also may have affected the results. In addition, the preliminary nature of our measures, particularly the problems with the CICS-B noted by Black (1990) and revealed by our item analysis, may have affected the results. 
Several points raised by our analysis seem important for future investigators of supervisor development. First, there was some degree of individual variation on each measure. Possible explanations for these variations include the influences of individual traits and differences in previous experiences such as counseling work setting (e.g., school vs. community mental health). Future researchers may need to consider individual variables that affect supervisors' conceptualizations of the supervision process (cf. Borders, 1991).

Second, researchers also may want to consider the importance of replicating studies at various training sites. Significant differences found between students' first self-efficacy ratings regarding supervision at the two universities suggest that there may be important variations in the type of students attracted to a particular program or in the training environment's influence on students. Caution should be taken in generalizing results from one supervisor training program.

Third, systematic work is needed to create valid supervision-specific instruments to measure various aspects of supervisor development. To date, supervision researchers typically have borrowed measures from the fields of counseling, education, and communication (e.g., Borders, 1991; Heppner \& Handley, 1981; Holloway, 1982; Holloway, Freund, Gardner, Nelson, \& Walker, 1989), but these measures have sometimes been inadequate for describing supervision variables (Borders, 1991; Ellis, 1991). Measures specific to supervisor development will require creativity and diligent work.

In summary, our descriptive data suggest that it would be fruitful to continue exploration of supervisors' cognitions, including novice and "expert" supervisors. Important questions for future work include identifying specific elements of the proposed "cognitive shift," how long this transition takes, and when it happened for experts. Such discovery-oriented efforts will be crucial to building an empirically-based theory of supervisor development and, eventually, determining what training experiences positively influence development. This study has supported the need for such efforts and has provided preliminary baseline data for future work.

\section{TABLE 1}

Mean Proportions of Students' Thought-Listings in Each Dimension and Category at Pretest and Posttest

Pretest Posttest

$\begin{array}{lllll}\text { Categories } & M & \text { SD } & M & \text { SD }\end{array}$

Focus

$\begin{array}{lllll}\text { Client } & .08 & .13 & .05 & .10\end{array}$ 


$\begin{array}{lcccc}\text { Counselor } & .57 & .20 & .49 & .24 \\ \text { Counselor supervisor } & .23 & .27 & .18 & .20 \\ \text { Counselor-client } & .10 & .13 & .04 & .08 \\ \text { Parallel supervisor } & .03 & .07 & .05 & .09 \\ \text { Process } & .02 & .06 & .19 & .21\end{array}$

Content

$\begin{array}{lllllll}\text { Physical/Factual } & 03 & .06 & .03 & .06\end{array}$

$\begin{array}{lllll}\text { Roles/Habits behaviors } & .38 & .20 & .35 & .16\end{array}$

$\begin{array}{llllllllllllllll} & \text { Psychological traits } & & .34 & .24 & .49 & .22\end{array}$

$\begin{array}{lllll}\text { Interaction/Process } & .25 & .25 & .13 & .17\end{array}$

Tone

$\begin{array}{lllll}\text { Positive } & .00 & .00 & .00 & .00\end{array}$

$\begin{array}{llllll}\text { Negative.25 } & .25 & .34 & .05 & .07\end{array}$

$\begin{array}{lllll}\text { Neutral } & .75 & .34 & .95 & .07\end{array}$

Thinking Mode

$\begin{array}{lllll}\text { Assumptions/Judgments } & .16 & .17 & .11 & .12 \\ \text { Inquiry (Divergent) } & .35 & .33 & .42 & .39 \\ \text { Directive -- Given } & .08 & .10 & .00 & .00 \\ \text { Directive -- (Action) } & .41 & .38 & .46 & .39\end{array}$

Note. $\mathrm{N}=8$ for each category. 


\section{REFERENCES}

Alonso, A. (1983). A developmental theory of psychodynamic supervision. The Clinical Supervisor, 1(3), 23-36.

Alonso, A. (1985). The quiet profession: Supervisors of psychotherapy. New York: Macmillan.

Beck, A. T., \& Freeman. A. (1990). Cognitive therapy of personality disorders. New York: Guilford.

Bernard, J. M., \& Goodyear. R. K. (1992). Fundamentals of clinical supervision. Needham Heights, MA: Allyn \& Bacon.

Black, R. J. (1990). The development and initial validation of a critical incident questionnaire to assess counselor supervisor competence. Unpublished doctoral dissertation, Purdue University.

Borders, L. D. (1989). Learning to think like a supervisor. Paper presented at the annual convention of the American Psychological Association, New Orleans. LA.

Borders, L. D. (1991). Supervisors' in-session behaviors and cognitions. Counselor Education and Supervision, 31, 208-218.

Borders, L. D. (in press). Training programs for supervisors. In A. K. Hess (Ed.), Psychotherapy supervision: Theory, research and practice (Vol. II). New York: Wiley.

Borders, L. D., Bernard, J. M.. Dye, H. A., Fong, M. L., Henderson, P., \& Nance, D. W. (1991). Curriculum guide for training counseling supervisors: Rationale, development, and implementation. Counselor Education and Supervision, 31, 58-80.

Cacioppo, J. T., \& Petty, R. E. (1981). Social psychological procedures for cognitive response assessment: The thought-listing technique. In T. V. Merluzzi, C. R. Glass, \& M. Genest (Eds.), Cognitive assessment (pp. 309-342). New York: Guilford.

Carpenter, B. N., \& Suhr, P. (1988, August). Stress appraisal: Measurement and correlates. Paper presented at the annual meeting of the American Psychological Association, Atlanta, GA.

Dole, A. A. et al. (1982). Six dimensions of retrospections by therapists and counselors -- A manual for research. JSAS: Catalog of Selected Documents in Psychology, 12, 23. (Ms. No. 2454)

Duck, S. W. (1973). Personal relationships and personal constructs: A study of friendship formation. New York: Wiley.

Dye, H. A., \& Pride, K. (1987, April). ACES' attitudes: Supervisor competencies and a national certification program. Presentation at the annual meeting of the American Association for Counseling and Development, New Orleans, LA. 
Ellis, M. V. (1991). Critical incidents in clinical supervision and in supervisor supervision: Assessing supervisory issues. Journal of Counseling Psychology, 38, 342-349.

Heath, A. W., \& Storm, C. L. (1983). Answering the call: A manual for beginning supervisors. The Family Therapy Networker, 7(2). 36-37, 66.

Heppner, P. P., \& Handley, P. G. (1981). A study of the interpersonal influence process in supervision. Journal of Counseling Psychology, 28, 437-444.

Heppner, P. P., Rosenberg, J. I., \& Hedgespeth, J. (1992). Three methods in measuring the therapeutic process: Clients' and counselors' constructions of the therapeutic process versus actual therapeutic events. Journal of Counseling Psychology, 39, 20-31.

Hess, A. K. (1986). Growth in supervision: Stages of supervisee and supervisor development. The Clinical Supervisor, 4(1-2), 51-67.

Hess, A. K. (1987). Psychotherapy supervision: Stages, Buber, and a theory of relationship. Professional Psychology, 18, 251-259.

Hill, C. E. (1990). Exploratory in-session process research in individual psychotherapy: A review. Journal of Consulting and Clinical Psychology, 58, 288-294.

Holloway, E. L. (1982). Interactional structure of the supervision interview. Journal of Counseling Psychology, 29, 309-317.

Holloway, E. L., Freund, R. D., Gardner, S. L., Nelson, M. L., \& Walker, B. R. (1989). Relation of power and involvement to theoretical orientation in supervision: An analysis of discourse. Journal of Counseling Psychology, 36, 88-102.

Holloway, E. L., \& Wampold, B. R. (1983). Patterns of verbal behavior and judgments of satisfaction in the supervision interview. Journal of Counseling Psychology, 30, 227-234.

Mahrer, A. R. (1988), Discovery-oriented psychotherapy research. American Psychologist, 43, 694-702.

McColley, S. H., \& Baker, E. L. (1982). Training activities and styles of beginning supervisors: A survey. Professional Psychology, 13, 283-292.

Stoltenberg, C. (1981). Approaching supervision from a developmental perspective: The counselor complexity model. Journal of Counseling Psychology, 28, 59-65.

Stoltenberg, C. D., \& Delworth, U. (1987). Supervising counselors and therapists: A developmental approach. San Francisco, CA: Jossey-Bass.

Worthington, E. L., Jr. (1987). Changes in supervision as counselors and supervisors gain experience: A review. Professional Psychology, 18, 189-208. 


\section{By L. DIANNE BORDERS and MARGARET L. FONG}

L. DiAnne Borders is an associate professor of counselor education at the University of North Carolina at Greensboro, 228 Curry Building, Greensboro, NC 27412. Margaret L. Fong is professor and chair of the Department of Counseling and Personnel Services at the University of Memphis, Memphis, TN 38152. Portions of this study were presented at the annual convention of the American Counseling Association, Minneapolis, MN, April 1994. 